\title{
A Study of Nitrate Uptake from Aqueous Solutions Using Isotactic Polypropylene-based Anion Exchangers
}

\author{
Sunil K. Banyal ${ }^{1}$, Ghanshyam S. Chauhan ${ }^{1, *}$ and Rajiv K. Sharma ${ }^{2}$ \\ ${ }^{1}$ Himachal Pradesh University, Department of Chemistry, Shimla, 171005, India \\ ${ }^{2}$ DAV Post Graduate College, Jallandhar, Punjab, India
}

\begin{abstract}
Two series of efficient and cost-effective anion exchangers possessing biocidal properties are reported for the removal of nitrate ions from aqueous solutions. Isotactic polypropylene (IPP) was modified by graft copolymerization with poly(4-vinyl pyridine) using $\mathrm{Y}$-rays as initiator. The graft copolymers were functionalized further by reaction with sodium 2-bromoethane sulphonate or 2-Chloroethanol to generate, respectively, the zwitterionic or choline-analogous structure on the IPP backbone. The functionalized graft copolymers have exchangeable $\mathrm{Cl}^{-}$or $\mathrm{Br}^{-}$ions and possess antimicrobial properties due to their polycationic character. These exhibited structure-property relationship when evaluated as anion exchangers for $\mathrm{NO}_{3}{ }^{-}$ions of which the maximum was removed from the feed solution with the graft copolymer having the lowest percent grafting. But the nature of the counter anion present did not exhibit much difference in the nitrate uptake behaviour. A parametric study, to evaluate the effect of different conditions on nitrate uptake, was carried as a function of contact time, temperature, $\mathrm{pH}$ of medium and $\mathrm{NO}_{3}{ }^{-}$concentration. A high maximum exchange capacity of $14.77 \mathrm{mg} / \mathrm{g}$ and $13.62 \mathrm{mg} / \mathrm{g}$ was observed, respectively for the graft copolymers having $\mathrm{Br}^{-}$and $\mathrm{Cl}^{-}$as the counter anions, at $\mathrm{pH} 5.0$, $35^{\circ} \mathrm{C}$, and $20 \mathrm{ppm}$ of the nitrate ions after ten cycles. The materials also exhibited good reusability up to ten cycles. The kinetics and mechanism of nitrate removal was studied and the data was found to fit the pseudo-second order kinetics and Langmuir isotherm.
\end{abstract}

Keywords: Anion Exchanger, Isotactic Polypropylene, Maximum exchange capacity, Nitrate removal, Reusability, Pseudo-second order kinetics.

\section{INTRODUCTION}

Nitrate is one of the major pollutants of water. Hence its removal from the ground water is a huge challenge to make wastewater fit for human consumption. The major sources of nitrate in ground or drinking water are fertilizers, sewage or its occurrence in the natural state. Excess intake of nitrate through food and water causes ill-health effects especially in babies or the elderly people. The nitrate concentration in surface water is normally low $(0-18 \mathrm{mg} / \mathrm{l})$ but can reach high levels as a result of agricultural runoff, refuse dump runoff or contamination with human or animal wastes [1]. Various techniques such as ion exchange, reverse osmosis or electro-dialysis for the treatment of nitrate removal from wastewater have been reviewed [2-3]. The membrane processes, ultrafiltration [4] or reverse osmosis [5], have been reported to be effective in the removal of nitrate. A twostage treatment based on the combination of chemical and biological processes has also been reported to be an effective method [6]. Other processes reported include the use of biosorption [7], electrokinetic method [8], reductive removal using zero valent copper or iron [9-10]. However, anion exchange processes are more suitable for making water fit for drinking purposes by

*Address correspondence to this author at the Himachal Pradesh University, Department of Chemistry, Shimla, 171005, India; Tel: +911772830944; Fax:+911772830775; E-mail: ghanshyam_in2000@yahoo.com designing low cost processes and products [11]. Anion exchange processes have also been re-integrated with the catalytic or with biological processes [12]. Song, et al. [13]. reported selective removal of nitrate by using a novel macroporous acrylic anion exchange resin. Zhou et al. [14]. reported the use of a magnetic anion exchanger for the selective removal of nitrate. The natural polymers-based functional hydrogels, those offer the advantages of cost effective being of renewable nature, have been used as supports for efficient removal of nitrate [15-20]. These also offer an ease of modification by the polymer analogous reactions.

In view of the above discussion, in the present article two series of the new isotactic polypropylene (IPP)-based anion exchangers have been reported. These have been synthesized in order to combine the benefit of cost-effectiveness and efficiency as an anion exchanger. There are no reports in literature on a similar material for the nitrate removal though derivatized poly(acrylic acid)-grafted-PP has been used as cation exchanger [21] or the antibacterial properties of the nano-silver particles loaded-PP have been explored [22]. In the present case, IPP was modified by grafting with 4-vinyl pyridine (4-VP), a functional monomer, by variation of different grafting conditions and the candidate graft copolymers were further functionalized by quaternization with Sodium 2Bromoethanesulphoante and 2-Chloroethanol to 
generate two series of anion exchangers that have quaternary nitrogen with exchangeable $\mathrm{Br}^{-}$or $\mathrm{Cl}^{-}$. The graft copolymers thus synthesized are bifunctional and possess anion exchange and antimicrobial properties two most desirable attributes of material for use in wastewater treatment. The properties of the reported materials are attributed to the polycationic nature of poly(4-VP) grafted chains generated by the derivatization reaction with the above-stated two reagents.

\section{EXPERIMENTAL}

\section{Materials}

Isotactic polyproylene, IPP (National Rayon Corporation, Mumbai, India), 4-Vinyl pyridine, 4-VP (Merck, Schuchardt, Germany), potassium fluoride, 2chloroethanol (S.D. Fine, Mumbai), were used as received. De-ionized water was used in all the experiments. Reagents for the nitrate detection were supplied by the Anatech Laboratories, Hyderabad, India.

\section{Synthesis and Quaternization Reaction of Graft Copolymers}

IPP was irradiated along with a known amount of 4VP and water in Gamma Chamber. Different grafting conditions such as irradiation dose, monomer concentration or amount of water were varied one after the other to evaluate the optimum grafting conditions (Table 1). The graft copolymers were extracted with methanol or equal mixture of acetone and water by stirring for $2 \mathrm{~h}$ to remove any attached homopolymer. The graft copolymer was separated, dried and weighed. It was again subjected to homopolymer removal by the above-stated extraction process. The drying, weighing and extraction process was repeated till constant weight was obtained. The graft copolymers thus obtained were designated as PP-g-poly(4-VP). The amount of the \% poly(4-VP) grafted on the backbone polymer, IPP, is defined percent grafting $\left(\mathrm{P}_{\mathrm{g}}\right)$ and is expressed as:

$\mathrm{P}_{\mathrm{g}}=\frac{\text { Amount of polymer grafted }}{\text { Weight of backbone polymer }} \times 100$

The graft copolymers, with the highest $P_{g}$ from each of the grafting condition varied, that is irradiation dose, monomer concentration and volume of water and maximum volume of water, as per the details given in supplementary data, having $P_{g}$ of $58.00,128,150$ and 32.0, were taken separately and immersed in an excess, 1:5 weight ratio, of Sodium 2Bromoethanesulphonate or 2-Chloroethanol and reacted, to quaternize the tertiary nitrogen of grafted poly(4-VP) chains, in a temperature-controlled water

Table 1: Effect of Grafting Reaction Parameters on $\mathbf{P}_{\mathbf{g}}{ }^{*}$

\begin{tabular}{|c|c|c|c|c|c|}
\hline Sr. No. & $\mathrm{y}$-irradiation dose $(\mathrm{h})$ & Monomer (ml) & $\mathrm{H}_{2} \mathrm{O}(\mathrm{ml})$ & $P_{g}$ & $R_{g}\left(\mathrm{~mol} \mathrm{~L}^{-} \mathrm{s}^{-}\right) \times 10^{6}$ \\
\hline 1. & 8 & 1.0 & 10.0 & 10.00 & 1.4247 \\
\hline 2. & 16 & 1.0 & 10.0 & 20.00 & 1.4247 \\
\hline 3. & 24 & 1.0 & 10.0 & 18.00 & 0.8548 \\
\hline 4. & 32 & 1.0 & 10.0 & 20.00 & 0.7124 \\
\hline 5. & 40 & 1.0 & 10.0 & 32.00 & 0.9118 \\
\hline 6. & 48 & 1.0 & 10.0 & 58.00 & 0.9023 \\
\hline 7. & 56 & 1.0 & 10.0 & 16.00 & 0.3257 \\
\hline 8. & 64 & 1.0 & 10.0 & 10.00 & 0.1781 \\
\hline 9. & 48 & 0.5 & 10.0 & 08.00 & 0.1985 \\
\hline 10. & 48 & 1.5 & 10.0 & 78.00 & 1.7756 \\
\hline 11. & 48 & 2.0 & 10.0 & 98.00 & 2.1422 \\
\hline 12. & 48 & 2.5 & 10.0 & 128.00 & 2.6911 \\
\hline 13. & 48 & 3.0 & 10.0 & 120.00 & 2.4301 \\
\hline 14. & 48 & 3.5 & 10.0 & 106.00 & 2.0704 \\
\hline 15. & 48 & 2.5 & 0.0 & 58.00 & 5.1658 \\
\hline 16. & 48 & 2.5 & 5.0 & 150.00 & 5.1028 \\
\hline 17. & 48 & 2.5 & 15.0 & 56.00 & 0.8520 \\
\hline 18. & 48 & 2.5 & 20.0 & 40.00 & 0.4768 \\
\hline 19. & 48 & 2.5 & 25.0 & 32.00 & 0.3135 \\
\hline
\end{tabular}

${ }^{*}$ Candidate graft copolymers synthesized by variation of the grafting conditions where the entries are shown in the bold and blue font were further functionalized by reaction with 2-Chloroethanol or Sodium 2-Bromoethane sulphonate and used in the nitrate removal studies. The irradiation does rate was $1.728 \mathrm{k}$ Gy./h. 
bath, at $100{ }^{\circ} \mathrm{C}$ for $18 \mathrm{~h}$ or $50^{\circ} \mathrm{C}$ for $36 \mathrm{~h}$, respectively. The quaternized graft copolymers were extracted with excess water to remove the unreacted 2-Chloroethanol or Sodium 2-Bromoethanesulphonate and dried in an air oven. Evidence of grafting, post reaction with 2Chloroethanol or Sodium 2-Bromoethanesulphonate were obtained from FTIR spectra recorded on Nicollet 5700 , or from SEMs recorded on JEOL JSM-6380.

\section{Anion Exchange Studies}

Four candidate functionalized graft copolymers of different $P_{g}$, weighing $0.1 \mathrm{~g}$ each, from both the series were separately immersed in $25 \mathrm{~mL}$ of a known concentration of $\mathrm{KNO}_{3}$ solution for different time interval $(30,60,90,120$ or $150 \mathrm{~min})$ at a fixed temperature and solution $\mathrm{pH}$. After specific time interval, the graft copolymers were removed from the respective solutions. The concentration of the nitrate ions left out in the solution was measured by adding the reagent. The procedure is based on the DMP method which is akin to the ISO 7890-1:1986 method. The principle of the method is based on the reaction of nitrate with 2,6-Dimethylphenol to generate in situ 4-Nitro-2,6-dimethylphenol. That instantaneously develops colour and the resultant direct concentration of nitrate was measured by colorimetric determination at $324 \mathrm{~nm}$ in Photolab 6600 UV-visible spectrophotometer. Percent uptake $\left(P_{\mathrm{u}}\right)$ and other parameters were calculated as shown below:

Percent uptake $\mathrm{P}_{\mathrm{u}}=\frac{\text { Amount of } \mathrm{NO}_{3}^{-} \text {removed }}{\text { Total amount of } \mathrm{NO}_{3}^{-} \text {in solution }} \times 100$
Partition Coefficient $\left(\mathrm{K}_{\mathrm{d}}\right)=\frac{\text { Amount of } \mathrm{NO}_{3}^{-} \text {removed }}{\text { Total amount of } \mathrm{NO}_{3}^{-} \text {in feed solution }}$

$\times \frac{\text { Volume of solution in } \mathrm{mL}}{\text { Weight of dry polymer }(\mathrm{g})}$

Exchange Capacity $(\mathrm{Q}) \mathrm{mg} \mathrm{g}^{-1}=\frac{\left(C_{o}-C_{t}\right) \mathrm{V}}{m}$

$Q$ is the amount of $\mathrm{NO}_{3}{ }^{-}$exchanged onto unit dry mass of the graft copolymer; $\mathrm{C}_{o}$ and $\mathrm{C}_{t}$ are the concentrations of ions $\left(\mathrm{mg} \mathrm{L}^{-1}\right)$ in the feed solution initially and after treatment for time $t$, and $V$ is volume of solution (L) and $m$ is the weight of dry graft copolymer used (g).

The graft copolymer from each series exhibiting the best results was used for the further studies to optimize conditions for the maximum nitrate uptake (Table 2). The effect of the temperature, $\mathrm{pH}$ and concentration was also varied, one at a time, over a range as per details presented in Table 3 . At the best conditions so obtained the maximum exchange capacity (MEC) of the selected materials was studied by using the same sample repeatedly for ten cycles. A single cycle was carried for $90 \mathrm{~min}$ at $35^{\circ} \mathrm{C}$ and in pH 5.0 and $20 \mathrm{ppm}$ of $\mathrm{NO}_{3}{ }^{-}$ions and $0.1 \mathrm{~g}$ of the sample. MEC was calculated by the following expression [17].

$\mathrm{MEC}=\frac{C_{m} \times V}{m}$

Where $\mathrm{C}_{o}$ and $\mathrm{C}_{t}$ are the concentrations of nitrate in the feed initially and after time $t, m$ is the weight of dry

Table 2: Effect of $\mathrm{P}_{\mathrm{g}}$ and Nature of Anion on the $\mathrm{P}_{\mathrm{u}}$ : Selection of Candidate Graft Copolymers for Further Anion Exchange Study

\begin{tabular}{|c|c|c|c|c|c|c|}
\hline S. No. & $\mathbf{P}_{\mathrm{g}}$ & $\mathrm{NO}_{3}^{-}(\mathrm{ppm})$ & $\mathrm{pH}$ & TDS (ppm) & Conductance ( $\mu \mathrm{s})$ & $\mathbf{P}_{\mathrm{u}}$ \\
\hline \multicolumn{7}{|c|}{$\mathrm{PP}-\mathrm{Br}$} \\
\hline 1. & 150.0 & 2.5 & 3.60 & 102.0 & 208.0 & 26.47 \\
\hline 2. & 128.0 & 2.2 & 3.64 & 110.0 & 220.0 & 35.29 \\
\hline 3. & 58.0 & 1.4 & 3.70 & 135.0 & 270.0 & 58.82 \\
\hline 4. & 32.0 & 1.0 & 3.72 & 141.0 & 281.0 & 70.59 \\
\hline \multicolumn{7}{|c|}{ PP-Cl } \\
\hline 1. & 150.0 & 2.4 & 3.56 & 229.0 & 458.0 & 29.41 \\
\hline 2. & 128.0 & 2.1 & 3.50 & 238.0 & 476.0 & 38.24 \\
\hline 3. & 58.0 & 1.4 & 3.42 & 252.0 & 504.0 & 58.82 \\
\hline 4. & 32.0 & 0.8 & 3.32 & 288.0 & 576.0 & 84.00 \\
\hline
\end{tabular}

${ }^{*}$ Conditions $=$ graft copolymer $0.1 \mathrm{~g}$, time $60 \mathrm{~min}, \mathrm{pH}, \mathrm{NO}_{3}{ }^{-} 5 \mathrm{ppm}$ and at $20^{\circ} \mathrm{C}$, dose rate $=1.728 \mathrm{k} \mathrm{Gy} . / \mathrm{h}$. 
Table 3a: Effect of Variation of Conditions on Resultant Physical Parameters of Solution Post Anion Exchange (PPBr)

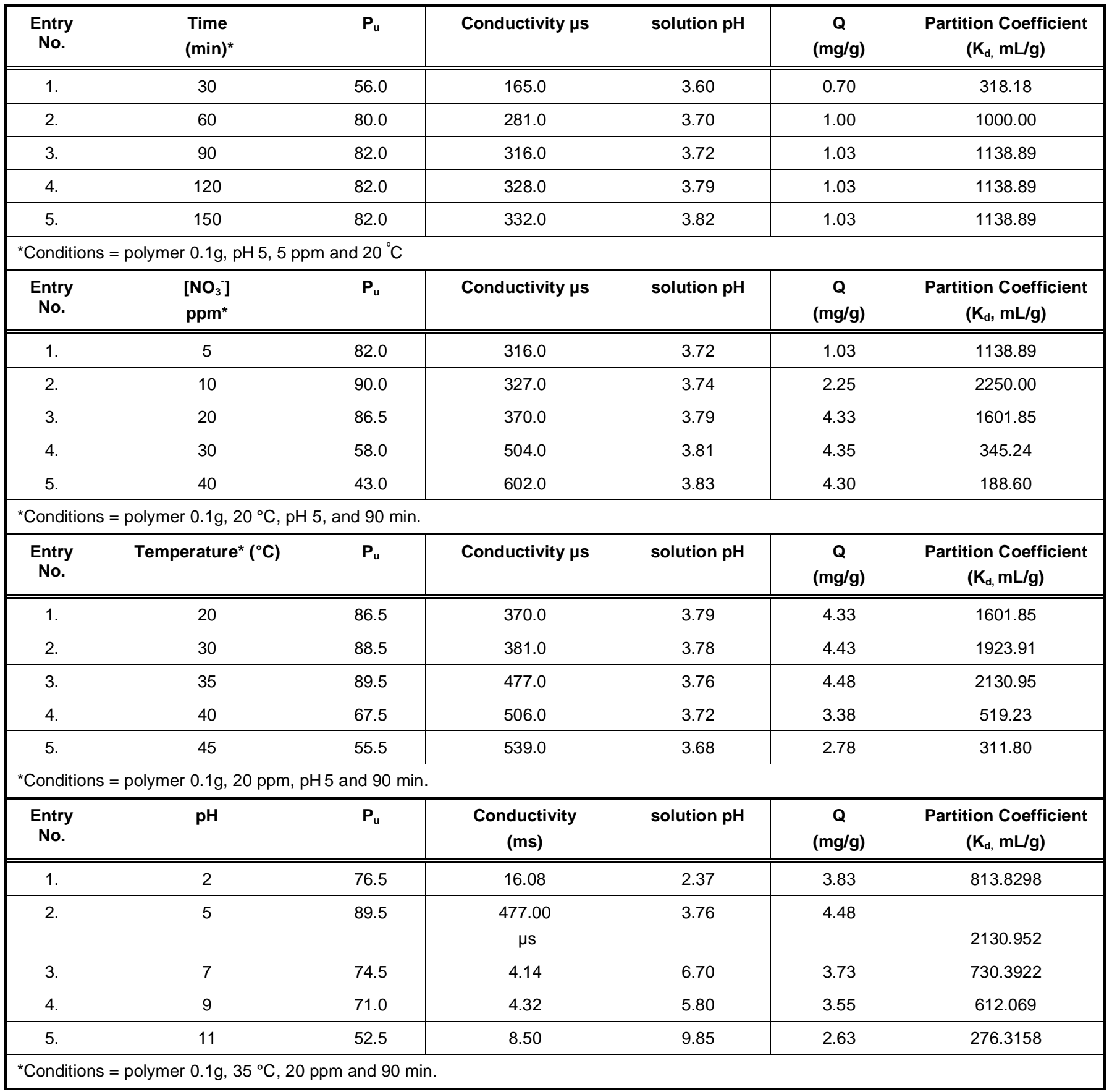

Table 3b: Effect of Variation of Conditions on Resultant Physical Parameters of Solution Post Anion Exchange (PP-Cl)

\begin{tabular}{|c|c|c|c|c|c|c|}
\hline $\begin{array}{c}\text { Entry } \\
\text { No. }\end{array}$ & $\begin{array}{c}\text { Time } \\
(\mathbf{m i n})\end{array}$ & $\mathbf{P}_{\mathrm{u}}$ & Conductivity $\boldsymbol{\mu s}$ & $\mathbf{p H}$ & $\begin{array}{c}\mathbf{Q} \\
(\mathbf{m g} / \mathbf{g})\end{array}$ & $\begin{array}{c}\text { Partition Coefficient } \\
\left(\mathbf{K}_{\mathrm{d}}, \mathbf{m L} / \mathbf{g}\right)\end{array}$ \\
\hline \hline 1. & 30 & 68.0 & 452.00 & 3.46 & 0.85 & 531.25 \\
\hline 2. & 60 & 84.0 & 576.00 & 3.32 & 1.05 & 1312.50 \\
\hline 3. & 90 & 86.0 & 708.00 & 3.29 & 1.08 & 1535.71 \\
\hline 4. & 120 & 86.0 & 722.00 & 3.27 & 1.08 & 1535.71 \\
\hline 5. & 150 & 86.0 & 730.00 & 3.26 & & 1.08 \\
\hline
\end{tabular}


(Table 3b). Continued.

\begin{tabular}{|c|c|c|c|c|c|c|}
\hline $\begin{array}{l}\text { Entry } \\
\text { No. }\end{array}$ & ppm & $\mathbf{P}_{\mathrm{u}}$ & Conductivity $\mu \mathrm{s}$ & $\mathrm{pH}$ & $Q(\mathrm{mg} / \mathrm{g})$ & $\begin{array}{l}\text { Partition Coefficient } \\
\qquad\left(\mathrm{K}_{\mathrm{d},}, \mathrm{mL} / \mathrm{g}\right)\end{array}$ \\
\hline 1. & 5 & 86.0 & 708.0 & 3.29 & 1.08 & 1535.71 \\
\hline 3. & 20 & 87.0 & 834.0 & 3.31 & 4.35 & 1673.08 \\
\hline 4. & 30 & 58.0 & 872.0 & 3.38 & 4.35 & 345.24 \\
\hline \multicolumn{7}{|c|}{${ }^{*}$ Conditions = polymer $0.1 \mathrm{~g}, \mathrm{pH} 5,20^{\circ} \mathrm{C}$ and $90 \mathrm{~min}}$. \\
\hline $\begin{array}{l}\text { Entry } \\
\text { No. }\end{array}$ & $\begin{array}{c}\text { Temperature } \\
\left({ }^{\circ} \mathrm{C}\right)\end{array}$ & $\mathbf{P}_{\mathrm{u}}$ & Conductivity $\mu \mathrm{s}$ & $\mathrm{pH}$ & $\begin{array}{c}Q \\
(\mathrm{mg} / \mathrm{g})\end{array}$ & $\begin{array}{l}\text { Partition Coefficient } \\
\qquad\left(\mathrm{K}_{\mathrm{d}}, \mathrm{mL} / \mathrm{g}\right)\end{array}$ \\
\hline 1. & 20 & 87.0 & 834.0 & 3.31 & 4.35 & 1673.08 \\
\hline 5. & 45 & 59.0 & 1134.0 & 3.20 & 2.95 & 359.76 \\
\hline \multicolumn{7}{|c|}{${ }^{*}$ Conditions $=$ polymer $0.1 \mathrm{~g}, \mathrm{pH} 5,20 \mathrm{ppm}$ and $90 \mathrm{~min}}$. \\
\hline $\begin{array}{l}\text { Entry } \\
\text { No. }\end{array}$ & $\mathrm{pH}$ & $\mathbf{P u}_{\mathbf{u}}$ & Conductivity $\mu \mathrm{s}$ & $\mathrm{pH}$ & $\begin{array}{c}Q \\
(\mathrm{mg} / \mathrm{g})\end{array}$ & $\begin{array}{l}\text { Partition Coefficient } \\
\qquad\left(\mathrm{K}_{\mathrm{d}}, \mathrm{mL} / \mathrm{g}\right)\end{array}$ \\
\hline 1. & 2 & 83.5 & $13.51 \mathrm{~ms}$ & 2.30 & 4.18 & 1265.15 \\
\hline 2. & 5 & 91.0 & $956.0 \mu \mathrm{s}$ & 3.25 & 4.55 & 2527.78 \\
\hline 3. & 7 & 78.5 & $3.50 \mathrm{~ms}$ & 5.10 & 3.93 & 912.79 \\
\hline 4. & 9 & 70.0 & $4.21 \mathrm{~ms}$ & 3.92 & 3.50 & 583.33 \\
\hline
\end{tabular}

polymer $(\mathrm{g}), \mathrm{C}_{m}$ is the anion concentration sorbed by the polymer, and $V$ is the total volume of the solution (L).

The reusability studies were carried for ten cycles using the same sample. After nitrate uptake in cycle 1 the sample was separated from the solution and it was stripped-off $\mathrm{NO}_{3}{ }^{-}$ions by immersion in the saturated $\mathrm{NaCl}$ solution for $1 \mathrm{~h}$ and sonicated. The regenerated sample was again used for nitrate uptake. The process for the regeneration and nitrate uptake was used for ten cycles as thereafter no nitrate was exchanged.

\section{RESULTS AND DISCUSSION}

Radiation grafting by $\mathrm{y}$-rays initiation is a clean and convenient method to modify natural or synthetic polymers to make these functional and useful for the target-specific applications. PP fibre is otherwise chemically inert and does not have functional groups. Modification or functionalization of PP by incorporation of the targeted functional groups is a desirable strategy to alter its application spectrum. In the present study, grafting of poly (4-VP) resulted in the maximum $\mathrm{P}_{\mathrm{g}}$ of $150 \%$ as a result of variation of different grafting parameters (Table 1). The effect of different grafting parameters is as per trends reported earlier. The grafting percent decreases after an optimum value when different parameters were changed. The same may be attributed to increase in the homopolymer formation [23]. The graft copolymers, PP-g-poly(4-VP), have comb-like structure with pendant poly(4-VP) groups attached to the IPP fibre backbone. To functionalize these graft copolymers by reaction with 2Chloroethanol or Sodium 2-Bromoethanesulphonate four graft copolymers having the highest $P_{g}$ obtained after the variation of a particular grafting parameter were chosen and reacted separately with the abovementioned two reagents. The quaternization reaction of the poly(4-VP) with 2-Chloroethanol or Sodium 2Bromoethanesulphonate takes place at the tertiary nitrogen of the pendant poly(4-VP) groups. The resulting polymers are henceforth designated as $\mathrm{PP}-\mathrm{Br}$ 
or $\mathrm{PP}-\mathrm{Cl}$ to distinguish the two series on the basis of the exchangeable anions. The graft copolymers $\mathrm{PP}-\mathrm{Br}$ or $\mathrm{PP}-\mathrm{Cl}$ are bifunctional with quaternary nitrogen and have $\mathrm{Br}^{-}$or $\mathrm{Cl}^{-}$as counter anions. These materials are non-toxic and have inherent anion exchange, antimicrobial or water softening properties which are most desirable attributes of a material usable in the drinking water treatment [24]. The course of the reaction and the structure of the resultant quaternized graft copolymers with the zwitterionic (PP-Br) or choline analogous (PP-Cl) pendant moieties are presented as Scheme 1.

\section{Characterization of Functional Graft Copolymers}

IPP and its different copolymeric forms were characterized by the elemental analysis, FTIR and SEM to obtain evidence of grafting and reaction with Sodium 2-Bromoethanesulphonate or 2-Chloroethanol. Elemental analysis provides evidence of different graft levels attained by variation of grafting conditions. For example, graft copolymers with $\mathrm{P}_{\mathrm{g}}$ of 10,58 , and 150 have $\% \mathrm{~N} 1.529,5.05$ and 7.392 that correlates with an increase in the grafted poly (4-VP). After the respective quaternization reaction the $\% \mathrm{~N}$ decreased in both PP$\mathrm{Br}$ and $\mathrm{PP}-\mathrm{Cl}$ with a higher decrease observed for the former. FTIR spectra of PP (and its graft copolymers were compared. PP backbone only has bands due to $\mathrm{CH}$ or $\mathrm{C}-\mathrm{C}$ stretching or bending vibrations, while its graft copolymers have also the bands of pyridine ring. The latter has bands at $1597.1,1556.1$ and $1492.8 \mathrm{~cm}^{-}$ ${ }^{1,}$ which are attributed to the stretching vibrations of the $-\mathrm{C}=\mathrm{N}$ and $-\mathrm{C}=\mathrm{C}$ bonds, and these on quaternization shifted to $1644.6 / 1646.4 \mathrm{~cm}^{-1} 1573.3 / 1571.7$ and $1515.9 / 1517.9,1455.9 / 1457.7$, for the pyridinium ions of PP-Cl/PP-Br. While there is a band at $820.3 \mathrm{~cm}^{-1}$ due to the substituted aromatic ring, which shifted to
$842.3 / 840.5 \mathrm{~cm}^{-1}$ in the spectra of PP-Br/PP-Cl [24]. In the spectra of the functionalized polymers, absorption peaks of a band attributed to the quaternary ammonium salts absorption is observed in at 2360 $\mathrm{cm}^{-1}$. SEMs of PP-g-poly(4-VP) and its quaternized forms are presented (Figure 1). The change in the morphology of the PP fibres is evident from the SEMs. The fibre diameter is more in the case of graft copolymers with the highest $P_{g}(150)$ than in ones with the lower graft levels (Figure 1a and b). The fibre surface on post-grafting and on quaternization with 2Chloroethanol or Sodium 2-Bromoethnaesulphonate shows changes on the fibre surface as a result of charge generation. SEM-EDS of graft copolymer quaternized by reaction with 2- Chloroethanol are presented as Figure 1c. The presence of $\mathrm{Cl}^{-}$can be evidenced from the EDS of the sample.

\section{Nitrate Uptake Studies and Selection of Candidate Materials}

The graft copolymers behave as anion exchanger a property that emanates from the presence of the $\mathrm{Br}^{-}$or $\mathrm{Cl}^{-}$counter anions present on the quaternary nitrogen. It was observed that graft copolymers exhibited structure-property relationship in the nitrate uptake. The graft copolymer with the low $\mathrm{P}_{\mathrm{g}}$ was observed to be most effective anion exchanger than the three other candidate graft copolymers studied with higher $\mathrm{P}_{\mathrm{g}}$ level. The reason for such behaviour, as aforementioned, is due to the comb-like shape of the graft copolymers. The graft copolymers of higher $\mathrm{P}_{\mathrm{g}}$ are expected to both high grafting density as well as longer pendant poly(4VP) chains than the graft copolymers of low $P_{g}$. The former have large number of active sites initially for the quaternization reaction and later for the anion exchange but are not approachable to the nitrate ions
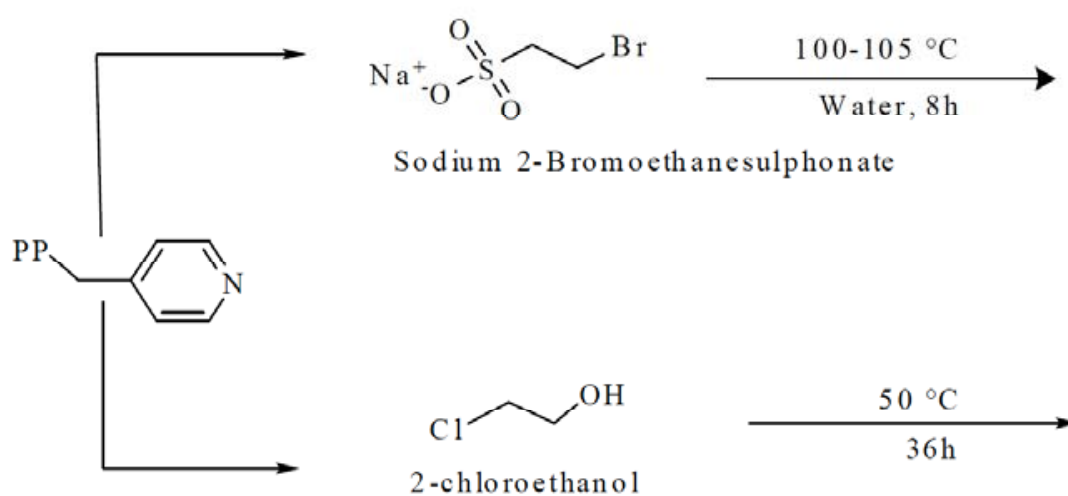

Sodium 2-Bromoethanesulphonate

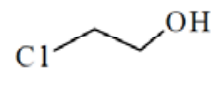

2 -chloroethanol

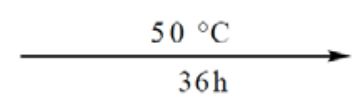

Scheme 1: Functionalization of IPP by quaternization reactions.

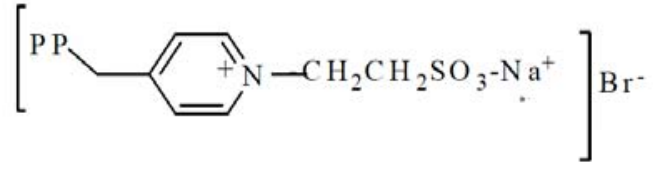

Poly (zwitterionic) structure

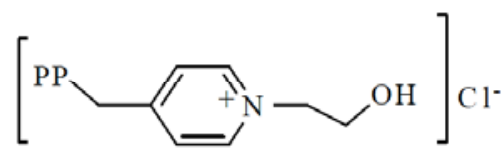

Choline analogous structure 


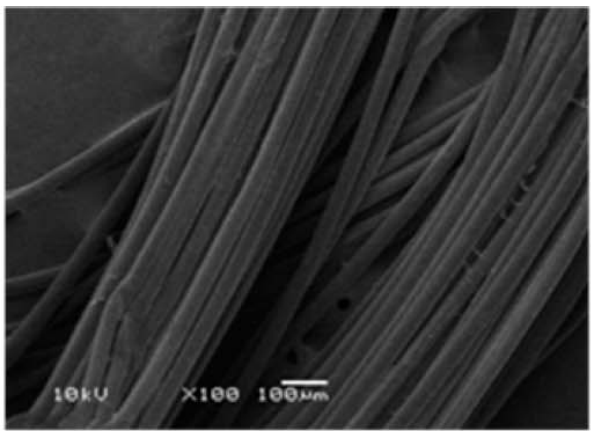

$\left(a_{1}\right)[\times 100]$

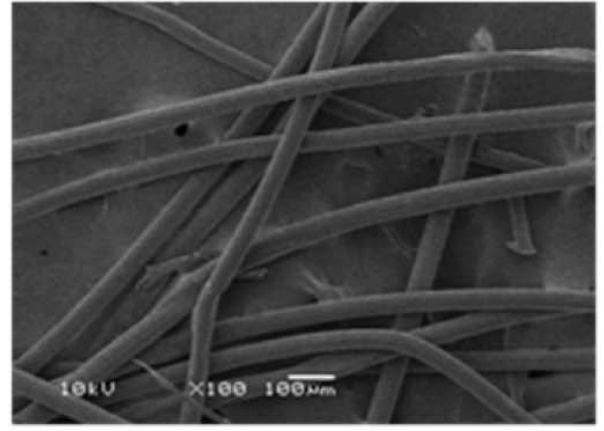

$\left(b_{1}\right)[\times 100]$

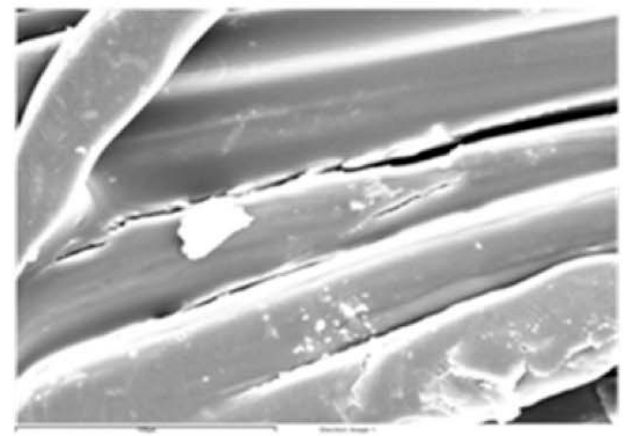

$\left(c_{1}\right)$

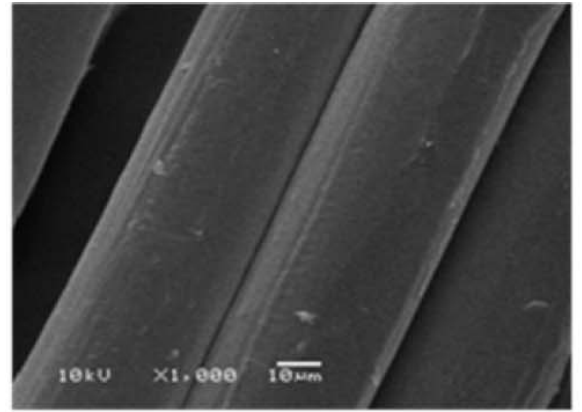

$\left(a_{2}\right)[\times 1000]$

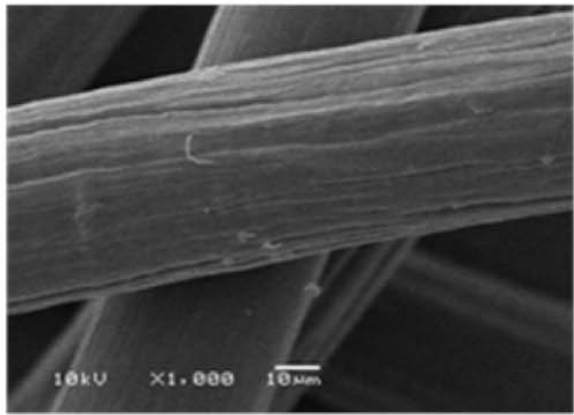

$\left(b_{2}\right)[\times 1000]$

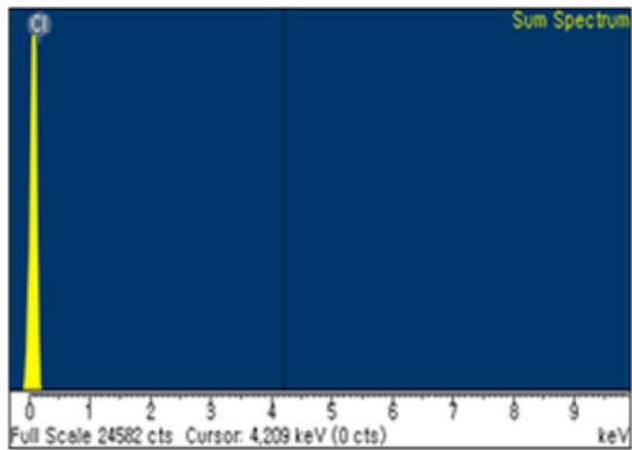

$\left(c_{2}\right)$

Figure 1: a) SEM images of IPP-g-poly(4-VP): a) $\left[P_{g}=32 \%\right]$, b) $P_{g}=150 \%$ and c) EDS-SEM quaternized form of (a).

due to the electrostatic as well as steric reasons [25]. Hence, the quaternized graft copolymer from both the $\mathrm{PP}-\mathrm{Br}$ and PP-Cl series having the lowest $\mathrm{P}_{\mathrm{g}}$ (32) exhibited the best $P_{u}$ (Table 2). This observation has technological potential as the cost effective functional graft copolymers can be designed with the lower $\mathrm{P}_{\mathrm{g}}$. These two materials were selected for the further studies. On the contrary, the extent of the anion exchange was not found to be markedly dependent on the nature of the counter anion present on the fibre.

\section{Effect of Different Parameters on Anion Exchange Capacity}

$\mathrm{NO}_{3}^{-}$uptake as a function of contact time is presented as Figure 2. The exchange of the anion was quite rapid as in the first 30 min more than $50 \%$ of anions were removed from the feed solution. $P_{u}$ was observed to increase with further increase of time and it reached equilibrium within $90 \mathrm{~min}$. Almost similar trends in results are reported for the $\mathrm{NO}_{3}$ uptake on hydrogels. The higher uptake of nitrate by $\mathrm{PP}-\mathrm{Cl}$ than $\mathrm{PP}-\mathrm{Br}$ with time variation may be attributed to the zwitterionic structure of the latter. An increase in the feed concentration of $\mathrm{NO}_{3}{ }^{-}$affected the nitrate uptake positively up to $20 \mathrm{ppm}$. Thereafter it remained constant though in $\mathrm{P}_{\mathrm{u}}$ terms it is apparent decrease, but in terms of $Q$ it is the same when concentration was increased over $20 \mathrm{ppm}$ (Figure 3). The effect of temperature on the $\mathrm{NO}_{3}{ }^{-}$uptake was studied from 20 ${ }^{\circ} \mathrm{C}$ to $45^{\circ} \mathrm{C}$. $\mathrm{P}_{\mathrm{u}}$ was observed to increase with an 


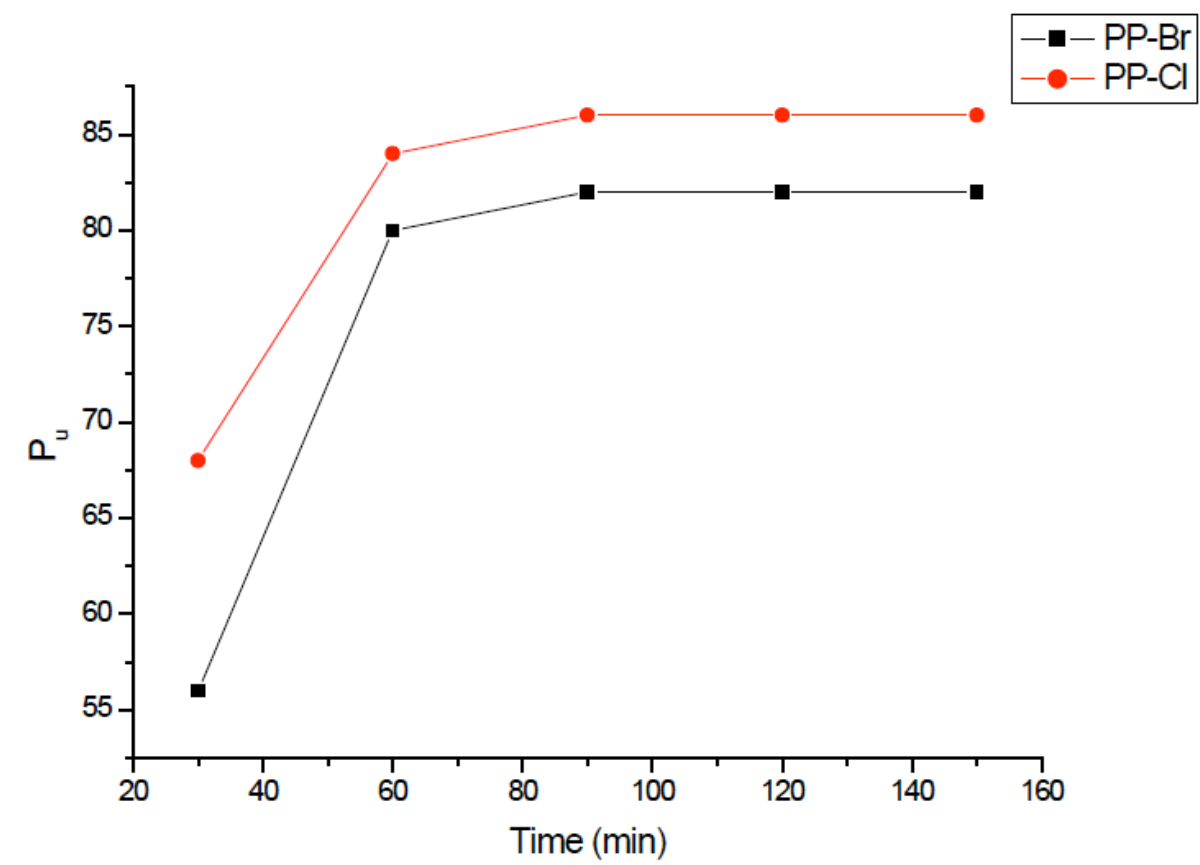

Figure 2: Effect of contact time on the nitrate uptake $\left[\mathrm{PP}-\mathrm{Br}\right.$ or $\mathrm{PP}-\mathrm{Cl}=0.1 \mathrm{~g}, \mathrm{pH}=5,\left[\mathrm{NO}_{3}{ }^{-}\right]=5$ and $\left.20^{\circ} \mathrm{C}\right]$.

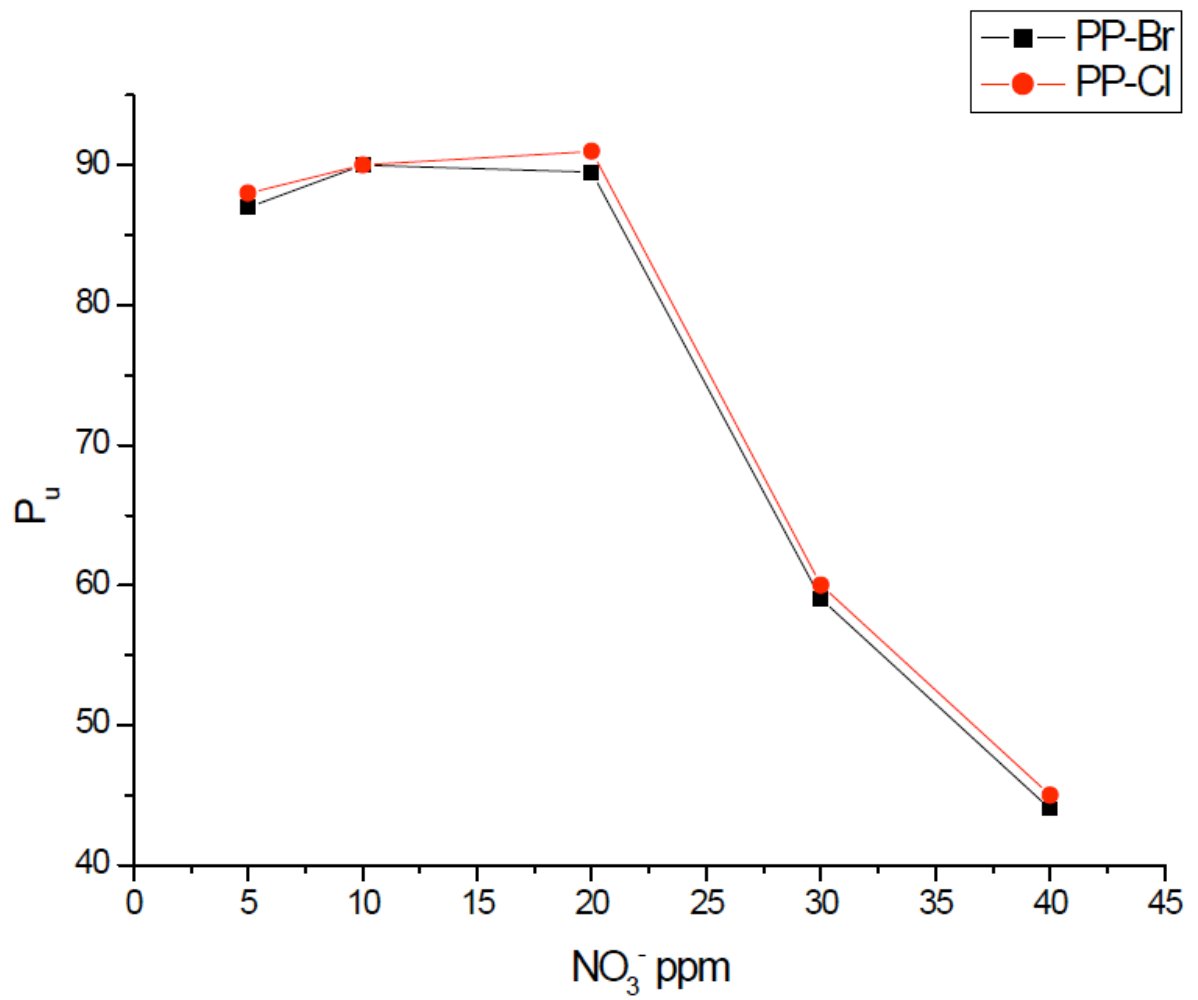

Figure 3: Effect of nitrate concentration on the nitrate uptake [PP-Br or PP-Cl $=0.1 \mathrm{~g}, \mathrm{pH}=5,20^{\circ} \mathrm{C}$ and time $\left.=90 \mathrm{~min}\right]$.

increase in temperature up to $45 \stackrel{\circ}{\circ}$ and thereafter it decreased with further increase in temperature. An increase in temperature beyond 35 으 though decreased $\mathrm{P}_{\mathrm{u}}$ yet it was significantly high, that is, more than $50 \%$ at the higher temperature $40{ }^{\circ} \mathrm{C}$ (Figure 4). Probably increase in temperature beyond a level result in decrease in ion uptake due to an increase in the kinetic energy of the feed solution resulting in lower ion adsorption. Exothermic behaviour of nitrate uptake at moderately high temperature has been reported previously [20]. Effect on $\mathrm{P}_{\mathrm{u}}$ as a function of $\mathrm{pH}$ variation over a range from 2 to 11 was studied and 


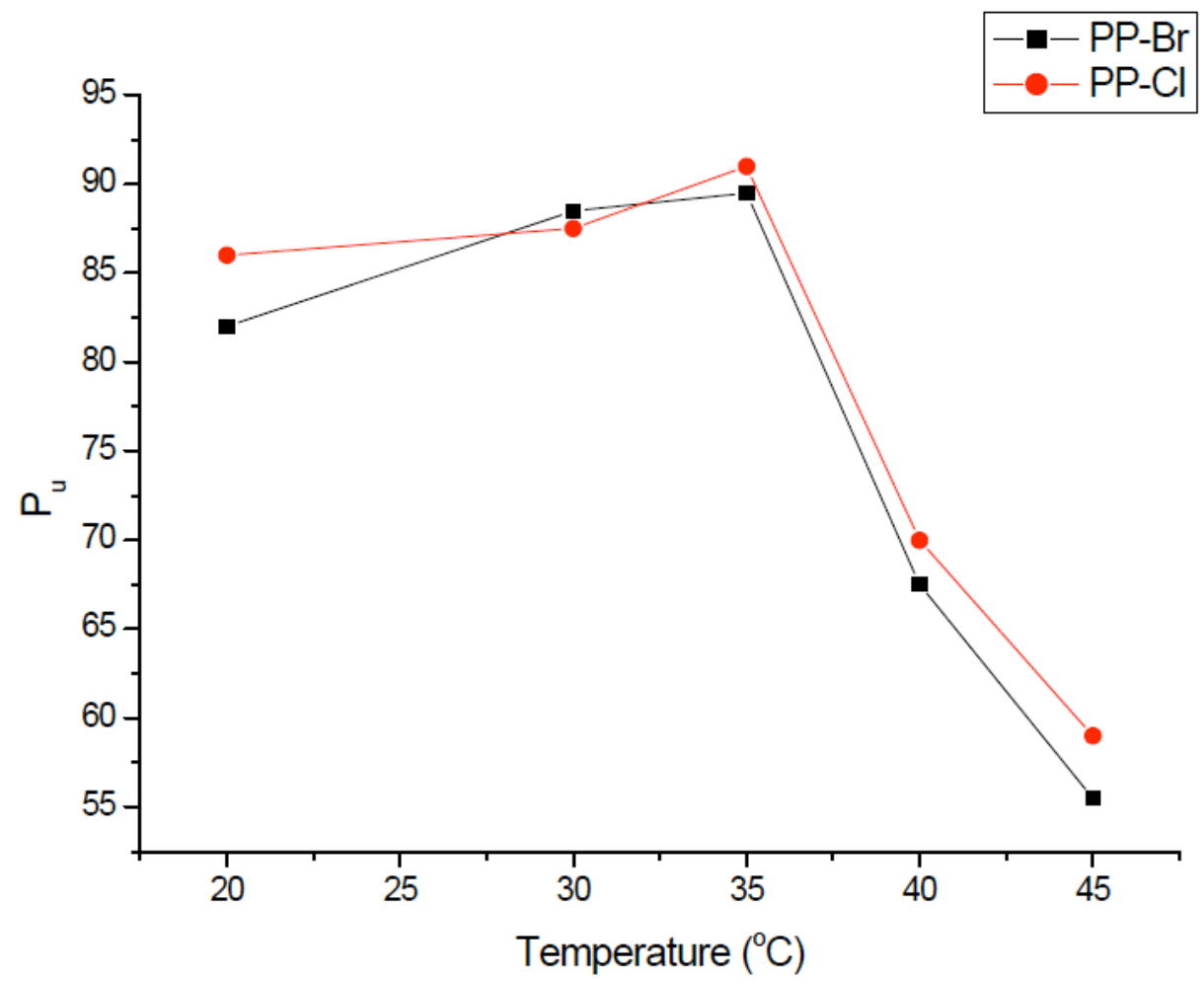

Figure 4: Effect of temperature variation on the nitrate uptake $\left[\mathrm{PP}-\mathrm{Br}\right.$ or $\mathrm{PP}-\mathrm{Cl}=0.1 \mathrm{~g}, \mathrm{pH}=5$, time $=90$ min and $\left[\mathrm{NO}_{3}{ }^{-}\right]=20$ ppm].

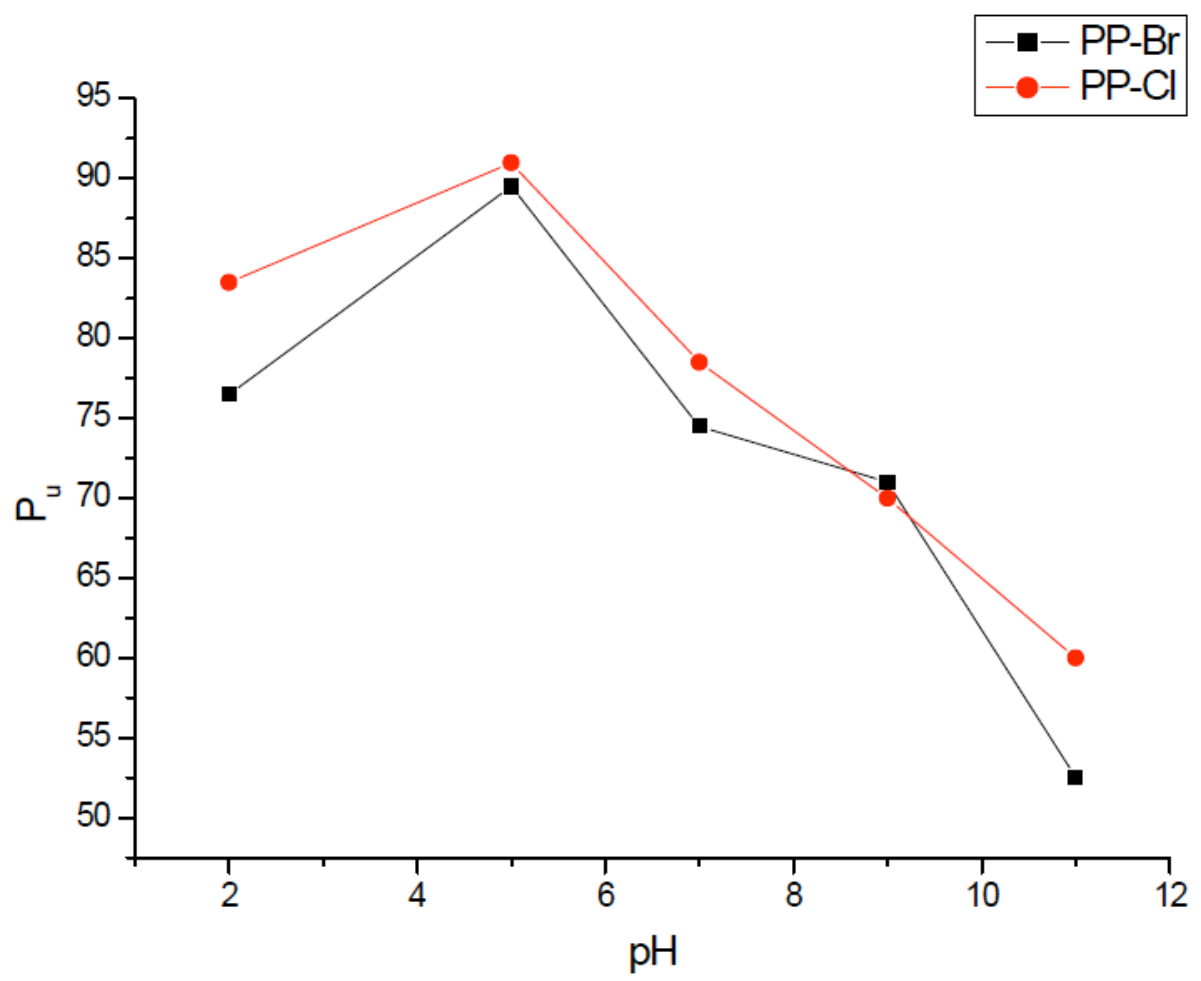

Figure 5: Effect of $\mathrm{pH}$ variation on the nitrate uptake $\left[\mathrm{PP}-\mathrm{Br}\right.$ or $\mathrm{PP}-\mathrm{Cl}=0.1 \mathrm{~g}$, time $=90 \mathrm{~min},\left[\mathrm{NO}_{3}{ }^{-}\right]=20 \mathrm{ppm}$ and temperature $\left.=35^{\circ} \mathrm{C}\right]$.

results are presented in Figure 5. There was an increase in $\mathrm{P}_{\mathrm{u}}$ initially with an increase in $\mathrm{pH}$ and the highest $\mathrm{P}_{\mathrm{u}}$, around 90 , was observed in the acidic at $\mathrm{pH}$ 5. However, thereafter it decreased with an increase of 
$\mathrm{pH}$ up to 11. It is apparent that at the higher $\mathrm{pH}$ the other anions of the medium also compete with the $\mathrm{NO}_{3}$ for the pyridinium ions on the graft chains.

\section{Evaluation of MEC and Reusability Studies}

From the above discussion it is apparent that the $\mathrm{P}_{\mathrm{u}}$ is affected only marginally by the nature of anion as PP-Cl exhibited slightly higher $\mathrm{NO}_{3}{ }^{-}$uptake than the $\mathrm{PP}-\mathrm{Br}$ when studied as function of various parameters. The best performance of both the materials studied was observed at $90 \mathrm{~min}, 35^{\circ} \mathrm{C}, \mathrm{pH} 5.0$, and $20 \mathrm{ppm}$ of $\mathrm{NO}_{3}{ }^{-}$. Hence, these parameters were used to evaluate the MEC of the two anion exchangers. MEC was studied by using repeatedly the same sample in ten cycles. In both the cases a reasonably high MEC of $14.77 \mathrm{mg} / \mathrm{g}$ and $13.62 \mathrm{mg} / \mathrm{g}$ for $\mathrm{PP}-\mathrm{Br}$ and $\mathrm{PP}-\mathrm{Cl}$ was obtained (Figure 6). These values obtained are lower than observed in a single uptake at $20 \mathrm{ppm}$ or higher concentration, but at different temperature as revealed from Figure 2. Both the materials studied are reusable as desorption of $\mathrm{NO}_{3}{ }^{-}$was studied up to ten cycles by treating the $\mathrm{NO}_{3}{ }^{-}$-loaded materials with the $\mathrm{NaCl}$ solution under sonication after each uptake cycle. The materials are reusable up to ten cycles in both the cases though PP-Cl exhibited slightly better behaviour than the PP-Br (Figure 7).

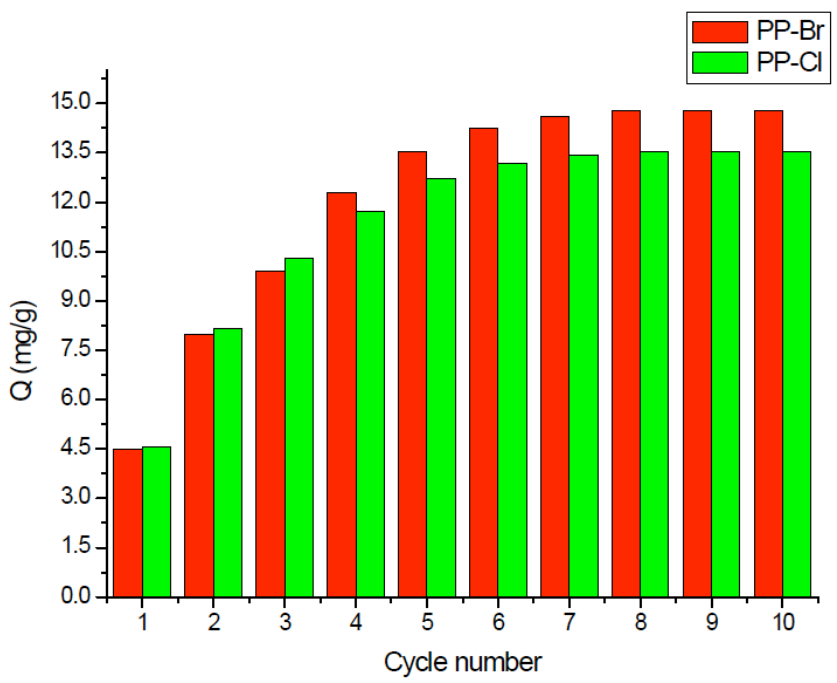

Figure 6: Evaluation of MEC of the nitrate uptake [PP-Br or $\mathrm{PP}-\mathrm{Cl}=0.1 \mathrm{~g}$, time $=90 \mathrm{~min},\left[\mathrm{NO}_{3}{ }^{-}\right]=20 \mathrm{ppm}$, temperature $=$ $35{ }^{\circ} \mathrm{C}$ and $\left.\mathrm{pH}=5\right]$.

\section{Mechanism of Anion Exchange and Evaluation of Applicability of Adsorption Isotherms and Kinetic Models}

IPP is a cost-effective hydrophobic material that resists water absorption. It has limited applications unless used as support to the active chains of grafted

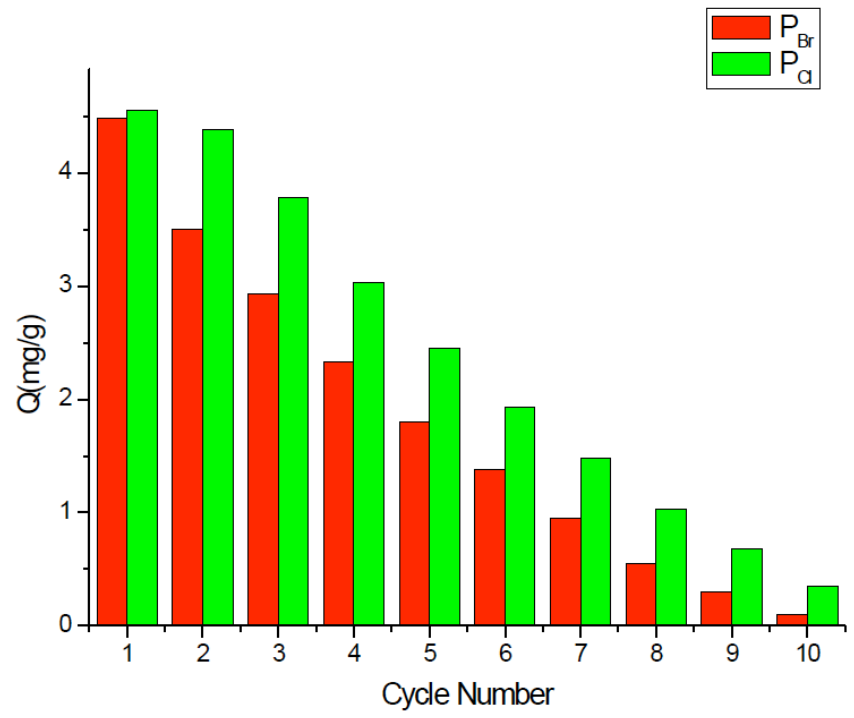

Figure 7: Evaluation of reusability of the nitrate after regeneration of support in different cycles with $\mathrm{NaCl}$ solution $\left[\mathrm{PP}-\mathrm{Br}\right.$ or $\mathrm{PP}-\mathrm{Cl}=0.1 \mathrm{~g}$, time $=90 \mathrm{~min},\left[\mathrm{NO}_{3}{ }^{-}\right]=20 \mathrm{ppm}$, temperature $=35^{\circ} \mathrm{C}$ and $\mathrm{pH}=5$ ]

polymers and their ionic forms. The solution properties such as $\mathrm{pH}, \mathrm{K}_{\mathrm{d}}$ and conductivity of the feed solution with the extent of anion exchange (Table 3). To evaluate the mechanism of nitrate removal by the graft copolymers Langmuir and Freundlich isotherm equations were tested to calculate $Q$ values at different feed concentration and the values so obtained were plotted along with the experimental values obtained [26]. The former assumes a weak physical binding of the anions on a surface with homogeneous layer formation. The latter, however, is a non-ideal phenomenon as the exchange of anions involves heterogeneous uptake over the active sites. The linear plots of $C_{\text {eq }} / Q$ versus $C_{\text {eq }}$, from the Langmuir equation $C_{\text {eq }} / Q=1 / Q_{\max } b+C_{\text {eq }} / Q_{\max }$, in both the anion exchangers matches the experimental data far better than the plot of $\log Q_{\mathrm{e}}$ vs. $\log \mathrm{C}_{\mathrm{e}}$ from the Freundlich equation, $\log Q_{\mathrm{e}}=\log K_{\mathrm{F}}+(1 / n) \log C_{\mathrm{e}}$, where $Q_{e}$ and $C_{e}$ are, respectively, equilibrium concentration and corresponding adsorption capacity. The consequent correlation coefficient values $\left(R^{2}\right)$ obtained from the two relationships are widely different with 0.98476 and 0.5399 , in $\mathrm{PP}-\mathrm{Br}$ and 0.99435 and 0.60352 in $\mathrm{P}-\mathrm{Cl}$, respectively, for the Langmuir and Freundlich equations. The comparison of the two isotherms with experimental is shown in Figures $\mathbf{8} \mathbf{a}$ and $\mathbf{8 b}$ with linearfit behaviour of the Langmuir isotherm shown in the inset.

The kinetics modeling was carried using the plot of $\log \left(q_{\mathrm{e}, 1}-q_{t}\right)$ versus $t$ for modelling the pseudo-firstorder equation, $\log \left(q_{\mathrm{e}, 1}-q_{t}\right)=\log q_{\mathrm{e}, 1}-\left(k_{1} / 2.303\right) t$, 

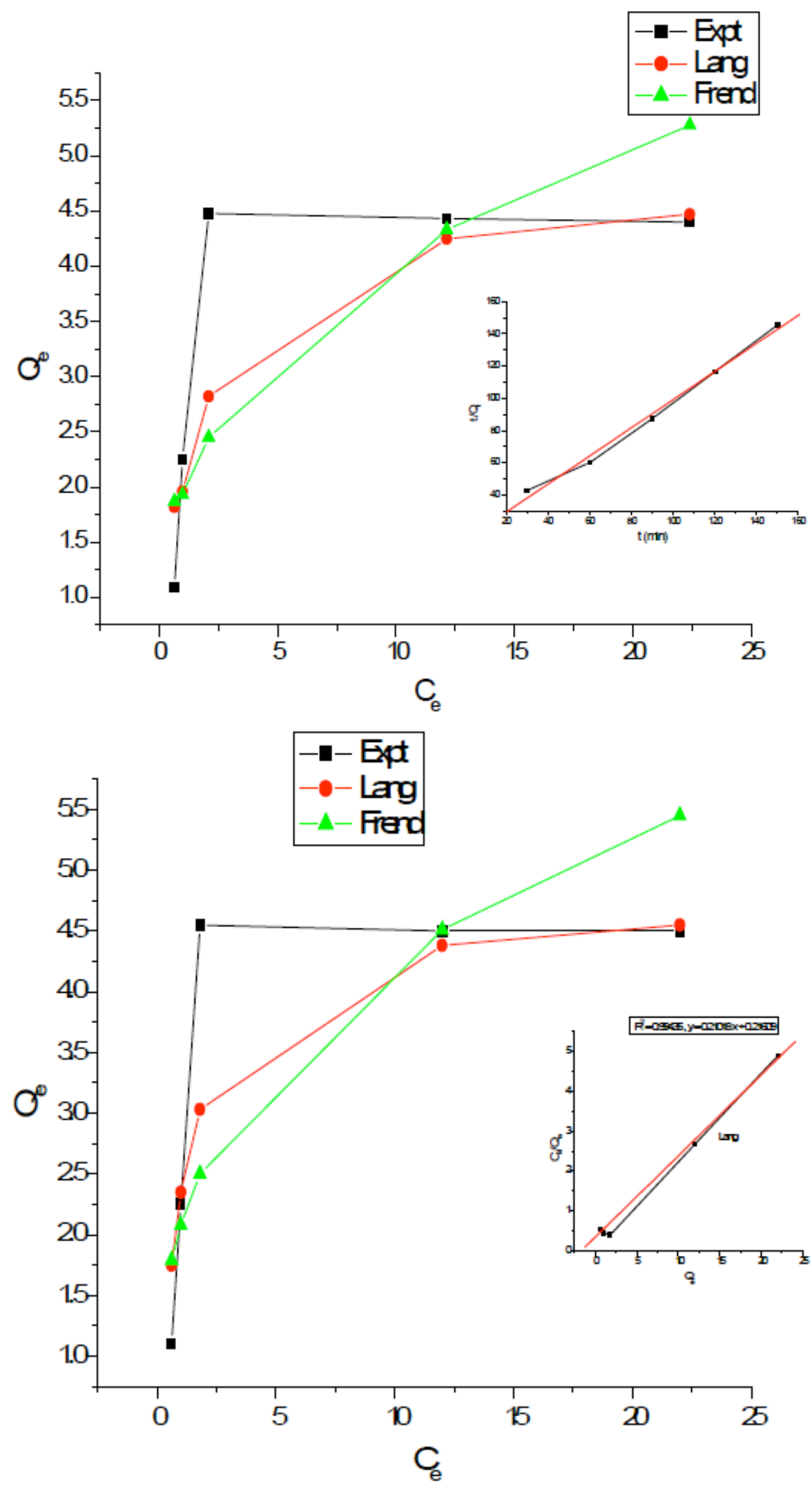

Figure 8: Comparison of experimental exchange capacity values with Langmuir and Freundlich isotherms for PP-Br (top) and $\mathrm{PP}-\mathrm{Cl}$ (bottom) [inset Langmuir linear-fit isotherm].

and plot of $t / Q_{t}$ versus $t$ from the linear pseudo-second order equation $t / q_{t}=1 / k_{2} q_{\mathrm{e}, 2}{ }^{2}+\left(1 / q_{\mathrm{e}, 2}\right) t$ was used. The terms $q_{e}$ and $q_{t}$ are exchange capacity at equilibrium and time $t$, and $k$ is respective rate constant. The 

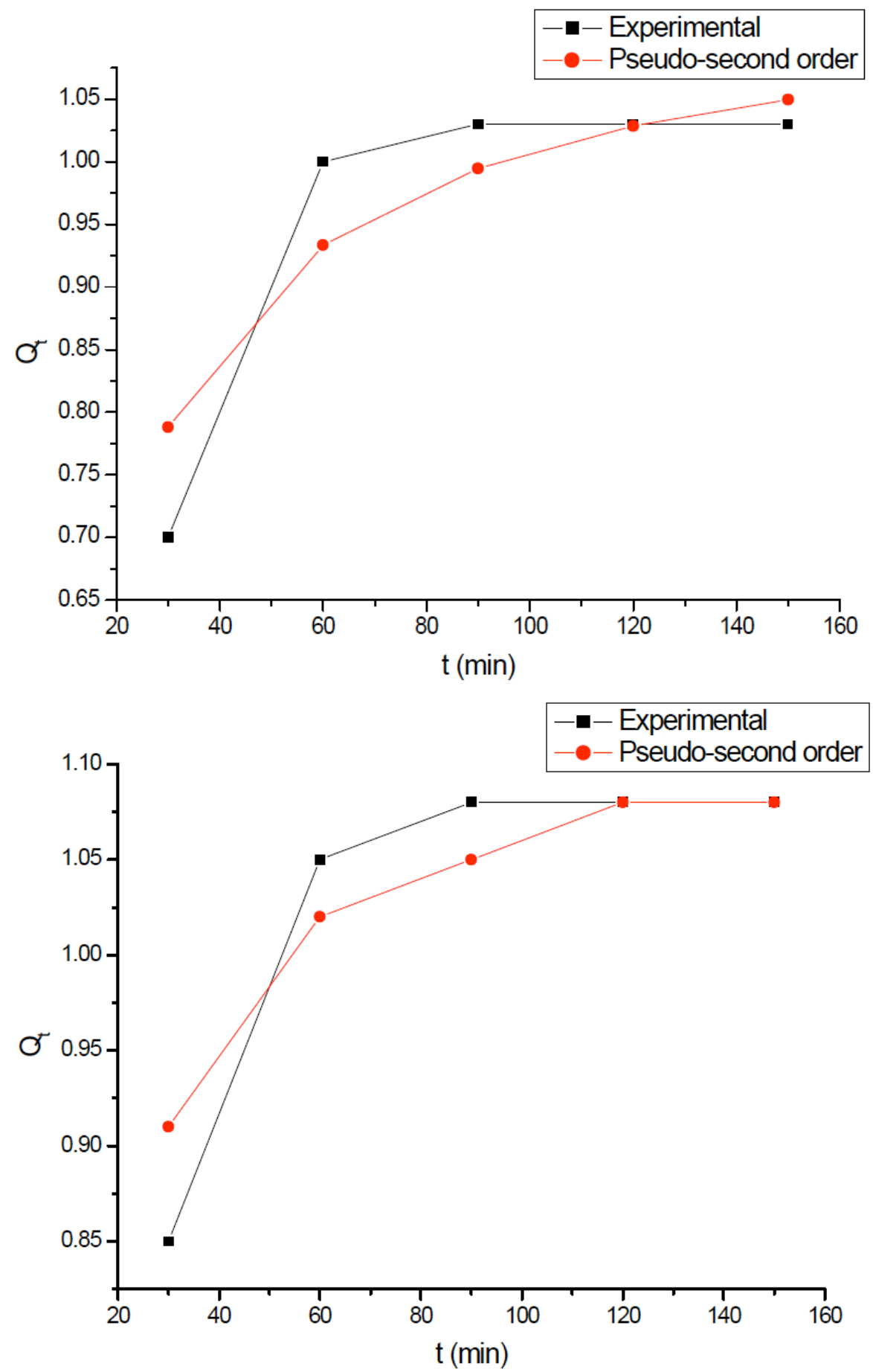

Figure 9: Comparison of experimental values with those obtained from pseudo-second order model PP-Br (top) and PP-Cl (bottom).

nitrate uptake followed the pseudo-second order kinetics. It was found to be applicable again in both the cases almost over the whole range of the contact time (Figure $9 \mathrm{a}$ and $9 \mathrm{~b}$ ). Similar conclusions have been made elsewhere [27]. The mechanism of the exchange reaction is depicted below:

As aforementioned this mechanism is also supported by the observation that after the completion of the experiments the $\mathrm{pH}$ and other parameters of the resultant solution were found to be different than the initial values (Table 2 ).

\section{CONCLUSIONS}

Isotactic polyproylene (IPP) fibres were graft copolymerized with poly(4-vinyl pyridine) by $\mathrm{V}$-ray initiation method. The grafted IPP was further 


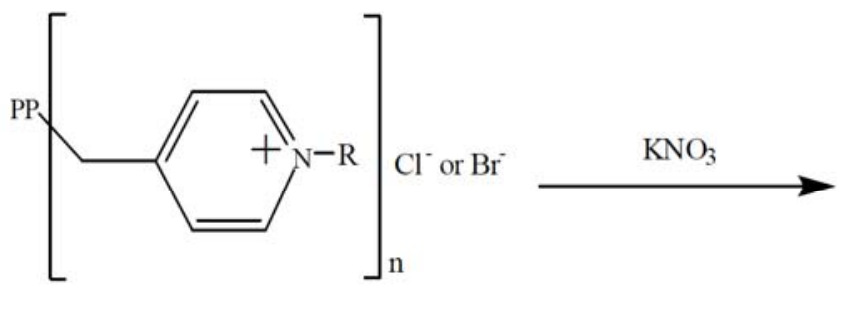

Where $\mathrm{R}=$ or $-\mathrm{CH}_{2} \mathrm{CH}_{2} \mathrm{SO}_{3} \mathrm{Na}^{+}$of PP-Br or $-\mathrm{CH}_{2} \mathrm{CH}_{2} \mathrm{OH}$ chain of PP-Cl

functionalized to polyzwitterionic and choline analogous materials having $\mathrm{Br}^{-}$or $\mathrm{Cl}^{-}$as the exchangeable ions. The resultant materials were evaluated as anion exchangers for the removal of nitrate ions from water. The nitrate uptake was only marginally dependent on the nature of anions, but the low graft level was observed to be far more efficient than the high graft level. A parametric study carried revealed dependence of the nitrate uptake on time, $\mathrm{pH}$, temperature and concentration of nitrate ions. The nitrate uptake by these materials was observed to be rapid as more than half ions were taken up within thirty minutes. It followed anion exchange mechanism. The data generated fits the Langmuir isotherm and pseudo-second order kinetics. Thus, the materials reported are low cost and efficient anion exchangers and have strong technological potential for use in water treatment technologies. Further, the study reported can be used to design low cost efficient anion exchangers.

\section{REFERENCES}

[1] WHO. Nitrate and Nitrite in Drinking-water Background document for development of WHO Guidelines for Drinkingwater Quality, World Health Organization, Geneva, Switzerland 2011.

[2] van der Hoek JP, Klapwijk A. Nitrate removal from ground water. Water Res 1987; 21: 989-97. http://dx.doi.org/10.1016/S0043-1354(87)80018-0

[3] Shrimali M, Singh KP. New methods of nitrate removal from water. Environ Poll 2001; 112: 351-59. http://dx.doi.org/10.1016/S0269-7491(00)00147-0

[4] Zhu X, Choo K-H, Park JM. Nitrate removal from contaminated water using polyelectrolyte-enhanced ultrafiltration, Desalination 2006; 193: 350-60. http://dx.doi.org/10.1016/j.desal.2005.06.067

[5] Ahn J-H, Choo KH, Park H-S. Reverse osmosis membrane treatment of acidic etchant wastewater: Effect of neutralization and polyelectrolyte coating on nitrate removal. J Membr Sci 2008; 310: 296-302. http://dx.doi.org/10.1016/j.memsci.2007.11.010

[6] Ayyasamy PM, Shanthi K, Lakshmanaperumalsamy P, Lee SJ, Choi NC, Kim DJ. Two-stage removal of nitrate from groundwater using biological and chemical treatments. J Biosci Bioengg 2007; 104: 129-34. http://dx.doi.org/10.1263/jbb.104.129

[7] Ayyasamy PM, Rajakumar S, Sathishkumar M, Swaminathan K, Shanthi K, Lakshmanaperumalsamy P, Lee S. Nitrate

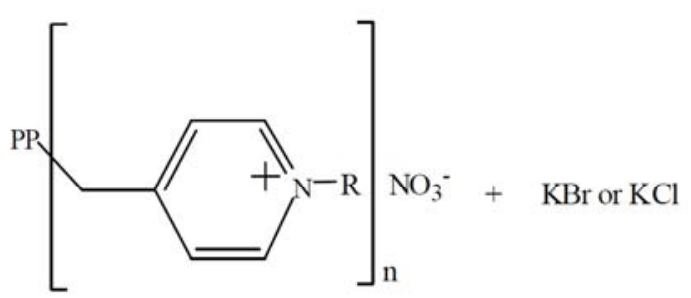

removal from synthetic medium and groundwater with aquatic macrophytes. Desalination 2009; 242: 286-96. http://dx.doi.org/10.1016/j.desal.2008.05.008

[8] Lee YJ, Choi JH, Lee HG, Ha TH, Bae JH. Pilot-scale study on in situ electrokinetic removal of nitrate from greenhouse soil. Sep Pur Technol 2011; 79: 254-63. http://dx.doi.org/10.1016/j.seppur.2011.02.011

[9] Fateminia S, Falamaki C. Zero valent nano-sized iron/clinoptilolite modified with zero valent copper for reductive nitrate removal. Proc Safety and Environ Protect In Press, Corrected Proof.

[10] Zhang Y, Li Y, Li J, Hu L, Zheng X. Enhanced removal of nitrate by a novel composite: Nanoscale zero valent iron supported on pillared clay. Chem Engg J 2011; 171; 526-31. http://dx.doi.org/10.1016/j.cej.2011.04.022

[11] Bae BU, Jung $\mathrm{YH}$, Han WW, Shin SH. Improved brine recycling during nitrate removal using ion exchange. Water Res 2002; 36: 3330-40. http://dx.doi.org/10.1016/S0043-1354(02)00012-X

[12] Pintar A, Batista J, Levec J. Integrated ion exchange/catalytic process for efficient removal of nitrates from drinking water. Chem Engg Sci 2001; 56: 1551-59.

http://dx.doi.org/10.1016/S0009-2509(00)00382-1

[13] Song HO, Zhou Y, Li AM, Mueller S. Selective removal of nitrate by using a novel macroporous acrylic anion exchange resin. Chin Chem Lett 2012; 23: 603-06. http://dx.doi.org/10.1016/i.cclet.2012.03.004

[14] Zhou Y, Shuang CD, Zhou Q, Zhang MC, Li, PH, Li AM. Preparation and application of a novel magnetic anion exchange resin for selective nitrate removal. Chin Chem Lett 2012; 23: 813-16.

http://dx.doi.org/10.1016/j.cclet.2012.05.010

[15] Chauhan GS, Chauhan S, Kumar S, Kumari A. A study in the adsorption of $\mathrm{Fe}^{2+}$ and $\mathrm{NO}_{3}^{-}$on pine needles based hydrogels. Bioresour Technol 2008; 99: 6464-70. http://dx.doi.org/10.1016/i.biortech.2007.11.044

[16] Chauhan GS, Kumar R, Verma M. A Study on the sorption of $\mathrm{NO}_{3}{ }^{-}$and $\mathrm{F}^{-}$on the carboxymethylated starch-based hydrogels loaded with $\mathrm{Fe}^{2+}$ ions. J Appl Polym Sci 2007; 106: 1924-31.

http://dx.doi.org/10.1002/app.26660

[17] Wang Y, Gao BY, Yue WW, Yue QY. Preparation and utilization of wheat straw anionic sorbent for the removal of nitrate from aqueous solution. J Environ Sci 2007; 19: 130510.

http://dx.doi.org/10.1016/S1001-0742(07)60213-7

[18] Chatterjee S, Woo SH. The removal of nitrate from aqueous solutions by chitosan hydrogel beads. J Hazard Mater 2009; 164: 1012-18 http://dx.doi.org/10.1016/j.jhazmat.2008.09.001

[19] Chatterjee S, Lee DS, Lee MW, Woo SH. Nitrate removal from aqueous solutions by cross-linked chitosan beads conditioned with sodium bisulphate. J Hazard Mater 2009, 166: 508-13.

http://dx.doi.org/10.1016/j.jhazmat.2008.11.045 
[20] Xu X, Gao B, Zhao Y, Chen S, Tan X, Yue Q, Lin J, Wang Y. Nitrate removal from aqueous solution by Arundo donax $L$. reed based anion exchange resin. J Hazard Mater 2012; 203-204: 86-92.

http://dx.doi.org/10.1016/j.jhazmat.2011.11.094

[21] Park HJ, Na CK. Preparation of anion exchanger by amination of acrylic acid grafted polypropylene nonwoven fiber and its ion-exchange property. J Colloid Interf Sci 2012; 301: 46-54.

http://dx.doi.org/10.1016/j.jcis.2006.05.003

[22] Wu JJ, Lee GJ, Chen YS, Hu TL. The synthesis of nanosilver/ polypropylene plastics for antibacterial application. Current Appl Phys In Press, Corrected Proof.

[23] Kaur I, Misra BN, Gupta A, Chauhan G. Graft copolymerization of 4-vinylpyridine and methyl acrylate onto polyethylene film by radiochemical method. J Appl Polym Sci 1998; 69: 599-10.

http://dx.doi.org/10.1002/(SICI)10974628(19980718)69:3<599::AID-APP20>3.0.CO;2-N
[24] Chauhan GS, Singh B, Dhiman SK. Functionalization of poly (4-vinyl pyridine) grafted cellulose by quaternization reactions and a study on the properties of post-quaternized copolymers. J Appl Polymer Sci 2003; 91: 2454-64.

http://dx.doi.org/10.1002/app.13406

[25] Odian G, Principles of polymerization, John Wiley \& Sons, NY 1981; pp. 658-659.

[26] Chauhan K, Chauhan GS, Ahn JH. Novel polycarboxylated starch-based sorbents for $\mathrm{Cu}^{2+}$ ions. Ind Eng Chem Res 2010; 49: 2548-56. http://dx.doi.org/10.1021/ie9009952

[27] Zheng Y, Wang A. Nitrate adsorption using poly(dimethy diallyl ammonium chloride) polyacrylamide hydrogel. J Chem Eng Data 2010; 55: 3494-500. http://dx.doi.org/10.1021/je100169r 